\title{
¿ESPAÑA CIRCULAR 2030? COMENTARIO AL BORRADOR DE LA ESTRATEGIA ESPAÑOLA DE ECONOMÍA CIRCULAR
}

\section{Circular Spain 2030? Comments to the Draft of the Spanish StRATEGy OF CIRCULAR ECONOMY}

\author{
BELTRÁN PUENTES COCIÑA \\ Investigador predoctoral del grupo ARMELA ${ }^{1}$ \\ Universidade de Santiago de Compostela \\ beltran.puentes@rai.usc.es
}

Recibido: 15 de octubre de 2018 / Aceptado: 7 de noviembre de 2018

RESUMEN: Tras el impulso conferido por las instituciones de la Unión Europea a la economía circular, corresponde a los Estados miembros la adopción de sus propias estrategias nacionales. A falta de un texto definitivo, la publicación del borrador de "España Circular 2030: Estrategia Española de Economía Circular" nos sirve de pretexto para estudiar el rumbo que lleva la transición hacia la economía circular en España. En el presente trabajo se realiza un análisis de las escasas reformas planteadas y algunas limitaciones encontradas en el borrador presentado por el anterior Gobierno del Estado, a fin de evaluar si un documento de esas condiciones sirve para dar respuesta a los desafíos planteados por las instituciones europeas.

RESUM: Després de l'impuls conferit per les institucions de la Unió Europea a l'economia circular, correspon als Estats membres l'adopció de les seves pròpies estratègies nacionals. A falta d'un text definitiu, la publicació de l'esborrany de "España Circular 2030: Estrategia Española de Economía Circular" ens serveix de pretext per analitzar el rumb que porta la transició cap a l'economia circular a

\footnotetext{
1 Este trabajo se integra en el proyecto "R2PI: Transition from linear 2 circular: Policy and Innovation" (ID 730378, Programa Marco de Investigación e Innovación de la Unión Europea Horizonte 2020) y de la ayuda concedida en el marco del programa "Consolidación e estruturación de unidades de investigación competitivas da Xunta de Galicia" (Ref. ED431B 2017/47).
} 
Espanya. En el present treball es realitza una anàlisi de les escasses reformes plantejades i algunes limitacions trobades en l'esborrany presentat per l'anterior Govern de l'Estat, per tal d'avaluar si un document d'aquestes condicions serveix per donar resposta als desafiaments plantejats per les institucions europeas.

ABSTRACT: European Union has given a strong impetus to circular economy strategy, so it is up to Member States to adopt their own national plans. In the absence of a definitive text, the publication of the draft of "España Circular 2030: Estrategia Española de Economía Circular" serves as a pretext to study the direction of the transition to the circular economy in Spain. The proposed reforms and some limitations found in the draft presented by the previous Government of the State are analysed in this work. It must be evaluated if a document of these conditions serves to respond to the challenges posed by the community institutions.

PALABRAS CLAVE: economía circular — estrategia nacional — plan de acción - Unión Europea

PARAULES CLAU: economia circular - estratègia nacional — pla d'acció Unió Europea

KEYWORDS: circular economy — national strategy — action plan — European Unión

SUMARIO: I. Introducción. II. Impulso y alcance del concepto de economía circular. 1. Impulso político-institucional. 2. Tensión entre sostenibilidad y competitividad. 3. Transversalidad y horizontalidad. III. Caracterización general de la estrategia. 1. Una estrategia a largo plazo: España Circular 2030. 2. Plan de Acción 2018-2020. IV. Notas características de la estrategia. 1. Reformas concentradas exclusivamente en el sector residuos. 2. Las implicaciones de la estrategia más allá del sector residuos. 3. Fiscalidad ambiental: entre la armonización y la falta de incentivos. 4. Un desplazamiento del poder de decisión del sector público. V. Conclusiones. VI. Bibliografía.

\section{INTRODUCCIÓN}

El actual modelo económico de extracción, producción, consumo y desecho corresponde a una época en la que los recursos se creían ilimitados y fáciles de obtener, pero hoy sabemos que esta secuencia lineal es incompatible con la protección del medio ambiente y con el carácter finito de los recursos. No sólo es deseable, sino que se ha vuelto necesario avanzar hacia un nuevo modelo 
que limite la extracción de nuevos materiales, optimice los recursos disponibles, minimice la generación de residuos y valorice los residuos generados. Estas son las premisas de las que parte toda estrategia de economía circular.

La Unión Europea ha acogido el término con entusiasmo², convirtiendo la transición hacia la economía circular en uno de los proyectos más destacados para superar la dependencia de la extracción e importación de materias primas, reactivar la economía tras la crisis económica y lograr un crecimiento inteligente, sostenible e integrador —objetivo más amplio fijado por la estrategia Europa $2020^{3}$ - El impulso de las instituciones comunitarias ha alentado a los Estados miembros a adoptar sus propias estrategias: varias ya han sido aprobadas y, en el caso de España, el anterior Gobierno del Estado inició el proceso de elaboración de la Estrategia Española de Economía Circular —en adelante, EEEC-. Aunque todavía no contamos con un texto definitivo, el borrador sacado a información pública en febrero de 2018 por los Ministerios de Agricultura y Pesca, Alimentación y Medio Ambiente y de Economía, Industria y Competitividad nos permite extraer algunas consideraciones ${ }^{4}$.

En este trabajo, a partir de una caracterización general del borrador de la EEEC, nos proponemos elaborar un primer diagnóstico del rumbo que lleva la transición hacia la economía circular en España y comprobar en qué medida estamos preparados para dar respuesta a la transformación demandada desde instancias comunitarias. Para acometer esta tarea, comenzaremos por introducir una serie de cuestiones previas sobre el alcance del concepto de economía circular y el impulso político-institucional que ha recibido a escala europea (v. infra apartado II). Esta primera aproximación conceptual nos permitirá más adelante, a la hora de abordar la caracterización general del documento español (v. infra apartado III), comprender la verdadera magnitud de las propuestas y valorar su carácter más o menos ambicioso. Por último, se expondrán algunas notas características

\footnotetext{
2 En este sentido, SANTAMARÍA ARINAS (2016: 45) señala que "[n]o se puede negar que tal concepto ha hecho fortuna en el discurso político europeo (que parece haber asumido con excesivo optimismo el reto del "cambio sistémico» que tales teorías reclaman)".

3 <https://eur-lex.europa.eu/legal-content/ES/TXT/?uri=celex\%3A52010DC2020> [Última consulta: 12.10 .2018$]$.

${ }^{4}$ El borrador de la EEEC se puede consultar en la página web del actual Ministerio para la Transición Ecológica: <https://www.miteco.gob.es/es/calidad-y-evaluacionambiental/participacion-publica/Residuos-2018-Nota-sobre-proceso-informacion-publicaestrategia-espanola-economia-circular.aspx> [Última consulta: 27.9.2018].
} 
que observamos en el documento presentado por el Gobierno del Estado (v. infra apartado IV) y que, a nuestro juicio, revelan algunas limitaciones que presenta la transición hacia la economía circular en España y que permitirán extraer, en el último apartado, algunas conclusiones al respecto.

\section{IMPULSO Y ALCANCE DEL CONCEPTO DE ECONOMÍA CIRCULAR}

\section{Impulso político-institucional}

La economía circular ha sido institucionalizada y promovida a nivel político por la Unión Europea desde la aprobación del "paquete revisado" ${ }^{2}$ de medidas para la economía circular de la Comisión Europea, a finales del año 2015. Este paquete estaba integrado por la Comunicación de la Comisión al Parlamento Europeo, al Consejo, al CESE y al CDR, de 2 de diciembre de 2015, "Cerrar el círculo: un plan de acción de la UE para la economía circular"6 y varias propuestas de revisión legislativa sobre los residuos.

El Plan de acción de la UE se encargaba de diseñar la hoja de ruta política que debe acompañar la estrategia, presentándola como una transformación sistémica con repercusión en todas las fases del ciclo económico y exhortando a los Estados miembros a adoptar estrategias, emplazamiento al que responde el objeto de estudio de este trabajo: "España Circular 2030: Estrategia Española de Economía Circular". Que todavía no se haya aprobado la estrategia nacional a estas alturas de 2018 —como han hecho países como Dinamarca, Finlandia, Luxemburgo, Países Bajos, Portugal, Escocia, Francia y regiones como Flandes- es elocuente sobre el grado de interés que ha mostrado el Gobierno del Estado por la economía circular. Por otra parte, comunidades autónomas

5 Se trata de un paquete "revisado" porque, anteriormente, se había aprobado un primer lote de
medidas integrado por la Comunicación de la Comisión al Parlamento Europeo, al Consejo, al
Comité Económico y Social Europeo (CESE) y al Comité de las Regiones (CDR), de 2 de julio
de 2014, "Hacia una economía circular: un programa de cero residuos para Europa" [Bruselas,
2.7.2014. COM(2014) 398 final] y varias propuestas de revisión legislativa, que fueron retiradas
antes de la aprobación del nuevo paquete. <https://eur-lex.europa.eu/legal-
content/es/ALL/?uri=CELEX\%3A52014DC0398> [Última consulta: 12.10.2018].
$6 \quad$ Bruselas, $2.12 .2015 . \quad \operatorname{COM}(2015) \quad 614 \quad$ final. lex.europa.eu/resource. html?uri=cellar:8a8ef5e8-99a0-11e5-b3b7-

01aa75ed71a1.0011.02/DOC_1\&format=PDF> [Última consulta: 12.10.2018] 
como Cataluña ${ }^{7}$ o Extremadura ${ }^{8}$ ya han presentado sus propias hojas de ruta para la economía circular.

La demora en la elaboración de la estrategia estatal pudiera deberse a un arduo trabajo de adaptación al plan europeo o a la elaboración de un ambicioso resorte de medidas para hacer efectivo el cambio de modelo, pero el contenido del borrador nos lleva a intuir que estamos, más bien, ante una respuesta tardía a la necesidad de cumplir con los compromisos políticos adquiridos a escala europea. Respuesta tardía que, por otra parte, tiende a ser habitual en la transposición o ejecución de las políticas ambientales de la UE, como podemos deducir del Informe anual sobre el control de la aplicación del Derecho de la UE en 2016 -últimos datos publicados-. Este informe sitúa a España como el país con más asuntos pendientes por transposición o aplicación incorrectas de la legislación de la $U E^{9} y$, entre las infracciones más relevantes, algunas tienen que ver con materias clave en la estrategia de economía circular: es el caso de los vertidos de aguas urbanas residuales que no habían recibido un tratamiento adecuado $^{10} \mathrm{o}$ la existencia de numerosos vertederos operativos que no cumplen los requerimientos de la Directiva de vertidos ${ }^{11}$.

Por otra parte, el caso de España también presenta un alto potencial de mejora, en términos de aprovechamiento y uso circular de los recursos, si atendemos al reducido porcentaje de residuos que son recuperados. Durante 2016, último año con datos publicados por Eurostat ${ }^{12}$, se reciclaron solamente el $29,7 \%$ de los residuos municipales generados, varios puntos por debajo de la media europea $(45,3 \%)$, Esta situación "significa que estamos desaprovechando gran parte de

\footnotetext{
7

<http://mediambient.gencat.cat/web/.content/home/ambits_dactuacio/empresa_i_produccio_sos tenible/economia_verda/impuls/IMPULS-EV_150519.pdf> [Última consulta: 12.10.2018].

$8 \quad<\mathrm{http}: / /$ extremadura2030.com/wp-content/uploads/2017/03/marco_070617_v.f_sinanexos.pdf> [Última consulta: 12.10.2018].

9 España acumulaba, a 31 de diciembre del 2016, un total de 91 asuntos pendientes (59 por transposición o aplicación incorrecta de la legislación europea y 32 por transposición tardía), cifra que le colocaba, junto a Alemania, en cabeza del ranking por incumplimientos del Derecho de la UE. Sólo en el 2016 le fueron abiertos 46 nuevos asuntos (12 por aplicación o transposición incorrecta y 34 por transposición tardía). $<$ https://ec.europa.eu/info/sites/info/files/file_import/national_factsheet_spain_2016_en_0.pdf> [Última consulta: 12.10.2018].

${ }^{10}$ Comisión vs España, C-38/15.

${ }^{11}$ Comisión vs España C-454/14.

12 Eurostat. Recycling rate of municipal waste. $<\mathrm{https}$ ://ec.europa.eu/eurostat/tgm/table.do?tab=table\&init=1\&language=en\&pcode=t2020_rt12 0\&plugin $=1>$ [Última consulta: 15.9 .2018 ]
} 
los recursos en un contexto en el que las materias cada vez son más escasas y caras" (MAPAMA y MINEICO, 2018: 27).

\section{Tensión entre sostenibilidad y competitividad}

Una de las notas características de la estrategia de economía circular es su intención de desplegar efectos en una doble dirección. En un intento de dejar atrás las dudas sobre la compatibilidad entre protección ambiental e intereses económicos, el nuevo modelo se presenta como una oportunidad para fomentar un uso eficiente y racional de los recursos naturales al tiempo se crea una fuente de beneficios empresariales.

En materia ambiental, la estrategia de economía circular da una vuelta de tuerca a las políticas comunitarias de las últimas décadas, estableciendo como objetivo la eliminación de todas las externalidades negativas que puedan surgir en el proceso productivo. En este sentido, el Plan de acción de la UE indica que la economía circular "ahorrará energía y contribuirá a evitar los daños irreversibles causados en lo relativo al clima y la biodiversidad, y a la contaminación del aire, el suelo y el agua, a causa de la utilización de los recursos a un ritmo que supera la capacidad de la Tierra para renovarlos" (CE, 2015: 2), además de repercutir positivamente sobre objetivos ligados como la reducción de los actuales niveles de emisiones.

Por otra parte, el concepto también nace fuertemente ligado al ámbito económico y empresarial. El Plan de acción de la UE enfatiza los beneficios económicos y de empleo que traerá consigo el cambio de modelo, como resultado de la reducción de la dependencia de materias primas y de los costes asociados a su extracción e importación. Basta con leer el primer párrafo del documento, que presenta la estrategia como una "oportunidad de transformar nuestra economía y de generar nuevas ventajas competitivas y sostenibles para Europa", para a continuación afirmar que "[l]a economía circular impulsará la competitividad de la UE al proteger a las empresas contra la escasez de recursos y la volatilidad de los precios, y contribuir a crear nuevas oportunidades empresariales, así como maneras innovadoras y más eficientes de producir y consumir" (CE, 2015: 2). 
Esta integración de aspectos ambientales y económicos supone, a nuestro modo de ver, una configuración más acabada del principio de sostenibilidad en su triple dimensión —económica, social y ambiental一. Como señala GARCÍA GARCÍA (2018: 311), "la economía circular es su evolución lógica, el presente y el futuro del principio de desarrollo sostenible". Siguiendo este razonamiento, la economía circular quizá constituye un enfoque más centrado en poner fin al despilfarro de recursos y superar la dependencia de las materias primas - que tan perniciosos efectos tiene sobre las economías europeas, como consecuencia de los elevados costes de importación-. De manera más precisa, SANTAMARÍA ARINAS (2016: 45) explica que "la economía circular no es más que una nueva manera de designar una exigencia elemental del viejo concepto de desarrollo sostenible como es la eficiencia en el uso de los recursos naturales. Una exigencia que, ante la indiscutible dependencia europea de los recursos importados, cobra mayor importancia económica y se presenta hoy como fórmula necesaria para la garantía de los suministros, el empleo, el crecimiento y la competitividad". En un sentido similar, DE SADELEER (2017: 233) considera que "[a]l colocar el recurso en el centro del desarrollo económico, este esquema debería servirle a Europa para abandonar el modelo del despilfarro. Después de la sociedad del usar y tirar, vendrá la sociedad sostenible. Las empresas europeas, ampliamente tributarias de la importación de materias primas con precios en constante fluctuación, saldrían ganando a la larga".

Los documentos oficiales presentan esta doble vertiente competitivo-sostenible de la economía circular como una oportunidad para aunar voluntades y consolidar la estrategia. En este sentido, tanto el Plan de acción de la UE como la EEEC hacen un esfuerzo pedagógico por mostrar los efectos positivos que traerá consigo la transición hacia la economía circular, confiando en que la combinación de intereses lleve a los diferentes gobiernos y empresas del sector privado a desarrollar políticas de circularidad. No obstante, cabe al menos cuestionar este optimismo y preguntarse sobre la compatibilidad de los intereses económicos con los estándares de protección ambiental, cuestión que ha sido abordada con mayor profundidad por otros autores. A los efectos que aquí interesan, merece la pena destacar la reflexión de KRAMER (2011: v, 397) sobre el carácter preponderante de la economía sobre el medio ambiente en caso de 
conflicto entre intereses ambientales e intereses económicos. El medio ambiente pierde en la práctica totalidad de los casos, en parte porque no tiene voz ni voto en el proceso de toma de decisiones, ni tiene detrás un grupo social fuerte que se encargue de defender sus intereses —como sí hacen los diferentes grupos de interés económico en sectores de alto impacto ambiental como la agricultura, la pesca, la industria o el transporte- .

\section{Transversalidad y horizontalidad}

El nuevo paradigma se configura de manera transversal, esto es, despliega sus efectos sobre el conjunto del ciclo productivo. El Plan de acción de la UE señala que "[l]as acciones propuestas apoyan la economía circular en cada etapa de la cadena de valor, desde la producción hasta el consumo, la reparación y la reelaboración, la gestión de los residuos y las materias primas secundarias que se reintroducen en la economía" (CE, 2015: 3). En este sentido, ORTEGA BERNARDO (2016: 65) indica que "es necesario subrayar que los cambios en materia de gestión de residuos no son las únicas reformas que se quieren implantar. Se quieren adoptar medidas que atiendan a todos los factores implicados en el problema, que se considera que es global. Por tanto se quieren incorporar otras iniciativas y mejoras adicionales que incidan en todo el ciclo de vida de un producto, de forma que efectivamente se pueda cerrar el círculo. Se abordan así distintas iniciativas que se proyectan tanto en la etapa última de consumo de los productos, incluyendo el fomento de los mercados de materias primas primarias y secundarias, junto a otras que promueven mejoras directamente sobre las fases de fabricación y elaboración”.

Si bien no se niega la importancia de las fases de recogida y tratamiento de residuos, el foco de la estrategia europea recae sobre las fases iniciales de producción y diseño: "[l]a economía circular comienza desde el principio mismo de la vida de un producto. Tanto la fase de diseño como los procesos de producción tienen un impacto sobre la obtención, la utilización de los recursos y la generación de residuos a lo largo de la vida de un producto" (CE, 2015: 4). El diseño ecológico es un elemento esencial de la economía circular, entendiendo que la mejor estrategia para reducir la cantidad de materiales desperdiciados consiste en concebir productos más duraderos y fácilmente reparables, con el 
fin de alargar al máximo su ciclo de vida útil y evitar que se conviertan en residuos con tanta celeridad.

Por otra parte, la estrategia también tiene un carácter horizontal, alcanzando sectores muy diversos. Entre las áreas de actividad que pueden verse afectadas por la transición circular, el Plan de acción de la UE destaca los plásticos, los residuos alimentarios, las materias primas críticas, la construcción y demolición, el sector de la biomasa y los bioproductos, la agroalimentación o el turismo.

En definitiva, la estrategia y las políticas públicas que se adopten bajo su impulso repercutirán sobre las distintas fases del ciclo productivo y también sobre una gran variedad de sectores de actividad, configurándose por tanto la economía circular como un paradigma de carácter transversal y horizontal. Esta amplia configuración del concepto de economía circular es clave para comprender la envergadura del "cambio sistémico" al que nos enfrentamos: "[l]a transición hacia una economía circular constituye un cambio sistémico. Además de las acciones específicas que afectan a cada una de las fases de la cadena de valor y los sectores clave, es necesario crear las condiciones en que la economía puede prosperar y los recursos pueden movilizarse" (CE, 2015: 21). En este sentido, acciones de carácter transversal como las políticas de $\mathrm{I}+\mathrm{D}+\mathrm{i}$, los programas de ayudas y financiación, los incentivos fiscales, la contratación pública ecológica, los programas de formación y las plataformas de colaboración entre diferentes actores se revelan como herramientas necesarias para avanzar en la transición hacia una economía más circular.

En esta línea, el diseño y la implementación de políticas de circularidad requiere la implicación de una amplia gama de actores institucionales y no institucionales, para lo que es necesario promover un enfoque integrado en la elaboración de políticas públicas. Sobre este concepto, GONZÁLEZ MEDINA (2018: 37) señala que no tiene una interpretación unívoca, sino que "el término unas veces se asocia a la promoción de mecanismos de colaboración o de inclusión de diversos actores en los procesos de elaboración de políticas públicas; mientras que, otras veces, se refiere más bien a la introducción de técnicas o dispositivos de gestión para lograr una mayor coherencia de las actuaciones y la optimización de los recursos económicos. En ese sentido, cabe señalar que la planificación estratégica puede incorporar las dos interpretaciones del término, en tanto que 
no solo sirve para construir marcos de concertación de intereses, sino que también provee herramientas para la gestión de proyectos (diagnóstico del problema, definición de objetivos, priorización, plan de acción, sistema de indicadores, etc.)". La planificación estratégica que realizan documentos como el Plan de acción de la UE y la EEEC parece responder a esa necesidad de un enfoque integral: por una parte, trazando una hoja de ruta común para los diferentes ámbitos de actuación e integrando las diferentes políticas sectoriales en un mismo documento; por otra parte, adoptando una serie de mecanismos de colaboración entre los diferentes actores implicados, que se revelan como marcos de actuación adecuados para la elaboración de una estrategia de estas características.

\section{CARACTERIZACIÓN GENERAL DE LA ESTRATEGIA}

La EEEC está integrada por dos grandes bloques. Mientras que el primero diseña la estrategia a largo plazo —-España Circular 2030"-, el segundo contiene un plan de acción con 70 medidas para el primer período de aplicación: 2018-2020. De un primer y somero análisis llama la atención el tono descriptivo que adopta el conjunto de un documento que, a lo largo de su amplia extensión -178 páginas-, parece limitarse a elaborar un diagnóstico sobre la situación actual, indicar alguna modificación legislativa que será preciso abordar como consecuencia de las obligaciones de trasposición de la normativa europea y emitir una declaración de intenciones sobre la voluntad de avanzar hacia un modelo económico más circular.

\section{Una estrategia a largo plazo: España Circular 2030}

La primera parte de la EEEC, la estrategia propiamente dicha, se estructura en siete apartados que abordan el concepto de economía circular en el contexto europeo e internacional, la situación actual en España y los sectores de actividad prioritarios, los objetivos, las políticas a implementar, los instrumentos, el modelo organizativo y los mecanismos de seguimiento. Los siguientes apartados se corresponden con la estructura de la EEEC. 
a) La economía circular en el marco internacional y europeo

El primer apartado, "De la Economía Lineal a la Economía Circular", sitúa la estrategia en el plano internacional como una respuesta sostenible y competitiva ante los efectos de la contaminación, el calentamiento global, los cambios demográficos y, sobre todo, la dependencia de la importación de materias primas y la volatilidad de los precios. Se desarrolla una visión positiva de la circularidad, como fuente de crecimiento, oportunidades empresariales y generación de empleo, en lo que parece un intento de atraer al sector privado hacia la circularidad.

Además, se menciona el Plan de Acción para la Economía Circular aprobado por la Comisión Europea como marco de referencia, del que se incorporan todas las propuestas legislativas sobre residuos y buena parte de las 54 medidas de desarrollo para las distintas fases del ciclo productivo. A escala europea también se destaca la alta participación de las entidades españolas en las convocatorias de financiación de actividades de investigación e innovación en los distintos ámbitos de la economía circular, al amparo del Programa Marco de Investigación e Innovación de la UE Horizonte 2020. Un 75,4\% de los proyectos financiados por la convocatoria específica Industria 2020 en la Economía Circular del ejercicio 2016-2017 han tenido presencia española, en su mayoría empresas un $46 \%$ del total de la financiación que ha recibido España fue a parar a entidades empresariales-.

\section{b) Situación en España y sectores prioritarios}

Como decíamos, la transición hacia la economía circular se concibe como un enfoque de carácter transversal y horizontal, consideración que motiva la distinción entre ejes de actuación y sectores prioritarios: mientras los primeros se corresponden con las distintas fases del ciclo productivo, los sectores prioritarios son aquellas áreas de actividad que, debido a los retos específicos a los que se enfrentan, serán objeto de una consideración especial. La EEEC combina un enfoque por etapas de la cadena de valor con una aproximación sectorial. 
Los ejes de actuación de la EEEC toman como referencia los cuatro que ya indicaba el Plan de acción de la UE —-producción, consumo, gestión de residuos y mercado de materias primas secundarias-, a los que se incorpora el fomento de la reutilización del agua por su relevancia en las economías del arco mediterráneo. No en vano, más de la mitad del presupuesto total de la estrategia (57\%) se destina al eje de actuación del agua. Por último, se incluyen tres ejes de carácter transversal: sensibilización y participación; investigación, innovación y competitividad; y empleo y formación.

Sobre estos ocho ejes pivotarán las medidas sectoriales, que se centrarán de forma prioritaria en cinco áreas de actividad: construcción y demolición, agroalimentación, industria en su conjunto, bienes de consumo y turismo. Esta aproximación sectorial presenta a priori dos aspectos controvertidos: por una parte, no parece del todo coherente seleccionar dos "sectores" que más bien se corresponden con fases del ciclo productivo: industria, que abarca buena parte de la fase de producción, y consumo. En cambio, de forma más relevante, se ignoran dos ámbitos prioritarios en el Plan de acción de la UE: plásticos y materias primas críticas.

\section{c) Objetivos estratégicos}

Los objetivos de la EEEC eluden toda concreción, constituyendo una serie de principios generales en materia de medio ambiente y residuos: protección del medio ambiente y la salud de las personas, análisis del ciclo de vida de los productos y ecodiseño, jerarquía de residuos, innovación y eficiencia de los procesos, consumo sostenible y responsable, coordinación interadministrativa, transparencia, concienciación y sensibilización, evaluación del impacto social y ambiental, políticas de empleo verde, etc. Se trata de principios que en sus elementos esenciales presiden el ordenamiento jurídico ambiental y de residuos de la UE desde hace décadas y sin duda deberán orientar también las políticas de circularidad, pero, como principios ordenadores, necesitan instrumentos y objetivos a corto plazo que los hagan efectivos. Al igual que sucedía con el "paquete de medidas" de la UE, será necesario salvar la distancia existente entre unos fines relativamente ambiciosos y los medios propuestos para alcanzarlos. En este sentido, SANTAMARÍA ARINAS (2016: 37) cuestionaba "si los modestos 
medios jurídicos dispuestos por el momento al efecto están a la altura que exigen los ambiciosos fines del «plan de acción»".

Por otra parte, los objetivos numéricos previstos en la EEEC se circunscriben al sector residuos, lo que remite, en definitiva, a una falta de asunción de lo que debería representar el salto a la economía circular con respecto a la, vieja, política de residuos. En concreto, a la hora de abordar las actuaciones previstas en materia de residuos, se hace referencia a los objetivos propuestos por el proyecto de revisión de la Directiva Marco de Residuos de la Unión Europea para la reutilización y el reciclado de residuos municipales para 2020 (50\%), 2025 (60 \%) y 2030 (65\%).

La consecución de estos fines requiere revisar el conjunto de normas que ordenan el sector residuos $y$, sobre todo, trabajar en un diseño que facilite la recuperación de los productos. El diseño debe ocupar un papel principal en el nuevo modelo productivo, toda vez que hasta el presente se habían invertido la mayoría de los esfuerzos en las fases finales del proceso productivo - gestión de residuos, reciclaje-. Así, para avanzar en ese verdadero "cambio sistémico", será necesario comenzar por una concepción ecológica del producto que tenga en cuenta el conjunto del ciclo de vida y fomente el alargamiento de la vida útil, la reparabilidad, la reducción de la obsolescencia, el concepto de servicio asociado al producto y la valorización de residuos. Sin embargo, llama la atención lo desapercibido que pasa el concepto de obsolescencia en la EEEC apenas se menciona en tres ocasiones-y, en particular, aquella obsolescencia programada por el fabricante para reducir deliberadamente la vida útil de los productos y acelerar su sustitución por parte del consumidor -no encontramos una sola referencia a este tipo de prácticas fraudulentas entre las 70 actuaciones propuestas para el primer subperíodo de aplicación-. Causa cierta desazón que el documento que pretende servir de base para una transformación de este calibre, con el horizonte puesto en 2030 , no siente las bases de unas políticas ambiciosas para paliar una situación que se revela clave en la lucha contra el despilfarro de recursos. Sobre esta cuestión volveremos más adelante (v. infra apartado IV.2.b). 
d) Políticas para el cambio

En la EEEC se destacan tres ámbitos de las políticas públicas que van a tener una especial incidencia en los sucesivos planes de acción: políticas ambientales, de competitividad y sociales.

Las políticas ambientales de la EEEC pivotan sobre los siguientes elementos: recursos renovables, contratación pública ecológica, valorización de residuos, aprobación de subproductos, reducción del desperdicio alimentario, reutilización del agua, empleo verde, protección de la biodiversidad y descarbonización de la economía. Más concretamente, se prevé revisar la normativa en materia de residuos con arreglo a las modificaciones introducidas por el legislador europeo; ejecutar actuaciones contempladas por programas existentes ${ }^{13}$; desarrollar nuevos sistemas productivos basados en el empleo de recursos renovables; impulsar la contratación pública ecológica; aprobar la consideración de subproductos; promover la gestión sostenible del agua; fomentar la información y transparencia para facilitar la decisión del consumidor; fomentar la sensibilización y participación ciudadana; crear "empleo verde" de calidad; desarrollar medidas para la protección y recuperación de la biodiversidad y los ecosistemas marinos; y alinearse con las políticas dirigidas hacia una economía baja en carbono.

Por otra parte, las políticas de competitividad se desarrollan en el marco del Plan Estatal de Investigación Científica y Técnica y de Innovación (2017-2020) ${ }^{14}$, que integra varios programas de ayudas. Entre ellos, el Programa Estatal de I+D+I orientada a los Retos de la Sociedad es el único que incluye referencias a la economía circular, en cuatro de los ocho retos formulados: Bioeconomía; Energía segura, eficiente y limpia; Transporte sostenible, inteligente y conectado; y Cambio climático y utilización de recursos naturales y materias primas. Así, el Programa prevé la financiación de proyectos relacionados con los parámetros de la economía circular en los citados ámbitos de actuación, remitiéndose también

\footnotetext{
13 Plan Estatal Marco de Gestión de Residuos 2016-2022, Programa de Prevención de Residuos 2014-2020, Estrategia "Más alimento, menos desperdicio" 2017-2020 y Estrategia Española de Crecimiento Azul, además del borrador del Plan de Contratación Pública Ecológica (2018-2025). ${ }^{14}$ El documento se puede consultar en la web del MINEICO:

<http://www.ciencia.gob.es/stfls/MICINN/Prensa/FICHEROS/2018/PlanEstatalIDI.pdf> [Última consulta: 9.10.2018]
} 
a la EEEC para "la identificación de las principales líneas de actuación en materia de I+D+i complementarias" (MINEICO, 2018: 75).

Por último, en relación a las políticas sociales, se hace hincapié en las políticas de activación del empleo, la responsabilidad social empresarial - a través de la Estrategia Española de RSE- y la seguridad y salud de los trabajadores, limitándose las propuestas a garantizar una mejor información, realizar actividades de formación, adecuar las políticas de educación y formación en el largo plazo, difundir campañas de sensibilización, realizar estudios o elaborar material de apoyo de carácter informativo y divulgativos.

\section{e) Instrumentos}

Los instrumentos para avanzar en la circularidad se conciben horizontalmente despliegan efectos sobre los diversos sectores de actividad-y se organizan en instrumentos normativos; financieros; de I+D+i; y de sensibilización, formación y divulgación.

La EEEC maneja una idea de instrumento normativo ligado a la vinculatoriedad y a su origen en el sector público: "[s]e definen los instrumentos normativos como las normas de carácter vinculante y aplicable directa o indirectamente sobre los individuos (físicos o jurídicos), sobre las Administraciones públicas e incluso sobre los propios poderes públicos, promovida desde el sector público, con independencia de su naturaleza" (MAPAMA y MINEICO, 2018: 64). Sin embargo, entre los instrumentos propuestos se reserva un papel importante para algunos de aplicación voluntaria -adhesión a sistemas voluntarios de certificación-y origen público-privado - estándares de obligado cumplimiento-. Por otra parte, las propuestas de revisión legislativa de carácter plenamente vinculante se limitan a las modificaciones de la normativa sobre residuos introducidas por el paquete europeo de economía circular ${ }^{15}$, que son de obligada transposición y,

\footnotetext{
${ }^{15}$ Recientemente, el 14 de junio de 2018, se han publicado en el DOUE seis actos legislativos aprobados por el Parlamento y el Consejo a propuesta de la Comisión, en el marco del paquete de medidas para la economía circular impulsado en diciembre del año 2015. Entre las normas aprobadas, se encuentran cuatro directivas que modifican varias directivas sobre residuos y que habrán de ser transpuestas por los Estados miembros en el plazo de 2 años:

a) Directiva (UE) 2018/849 del Parlamento Europeo y del Consejo, de 30 de mayo de 2018, por la que se modifican la Directiva 2000/53/CE relativa a los vehículos al final de su vida útil, la
} 
por tanto, remiten a la crítica que realizábamos sobre la ausencia de reflexión sobre el cambio de paradigma que la economía circular debe suponer con respecto a la mera gestión de residuos

Por otra parte, el papel que podrían jugar los instrumentos financieros proporcionando estímulo económico a las iniciativas privadas, bien mediante la concesión de ayudas, créditos, préstamos, subvenciones o instrumentos de naturaleza similar, bien a través de la política fiscal, se queda huérfano de previsiones concretas. Se trataría de configurar un marco económico y financiero que incentive las prácticas circulares entre los actores y empresas del sector privado. Sin embargo, la EEEC no contempla partidas propias para financiar ayudas económicas — sólo se remite a planes y programas sectoriales para su futura realización-y, en materia fiscal, las actuaciones previstas se limitan a realizar estudios sobre el actual sistema tributario y promover su armonización entre las diferentes comunidades autónomas y municipios. En la última parte de este trabajo retomaremos la cuestión de la tributación ambiental (v. infra apartado IV.3).

\section{f) Modelo organizativo}

La implementación de la EEEC será coordinada por un Comité de Dirección formado por las Direcciones Generales de Calidad y Evaluación Ambiental y Medio Natural, en representación del MAPAMA, y de Políticas de I+D+i, en representación del MINEICO. Para dar respuesta al carácter multisectorial de la

Directiva 2006/66/CE relativa a las pilas y acumuladores y a los residuos de pilas y acumuladores y la Directiva 2012/19/UE sobre residuos de aparatos eléctricos y electrónicos.

b) Directiva (UE) 2018/850 del Parlamento Europeo y del Consejo, de 30 de mayo de 2018, por la que se modifica la Directiva 1999/31/CE relativa al vertido de residuos.

c) Directiva (UE) 2018/851 del Parlamento Europeo y del Consejo, de 30 de mayo de 2018, por la que se modifica la Directiva 2008/98/CE sobre los residuos.

d) Directiva (UE) 2018/852 del Parlamento Europeo y del Consejo, de 30 de mayo de 2018, por la que se modifica la Directiva 94/62/CE relativa a los envases y residuos de envases.

Además, se han aprobado dos actos legislativos directamente aplicables:

e) Decisión (UE) 2018/853 del Parlamento Europeo y del Consejo de 30 de mayo de 2018 por la que se modifican el Reglamento (UE) n.o 1257/2013 y las Directivas 94/63/CE y 2009/31/CE del Parlamento Europeo y del Consejo y las Directivas 86/278/CEE y 87/217/CEE del Consejo, en lo que atañe a las normas de procedimiento en el ámbito de la información en materia de medio ambiente, y por la que se deroga la Directiva 91/692/CEE del Consejo.

f) Reglamento (UE) 2018/848 del Parlamento Europeo y del Consejo, de 30 de mayo de 2018, sobre producción ecológica y etiquetado de los productos ecológicos y por el que se deroga el Reglamento (CE) n.. 834/2007 del Consejo 
EEEC se constituye la Comisión Interministerial de Economía Circular, integrada por aquellos Ministerios ${ }^{16}$ cuyas políticas tienen efectos directos en la transición. Además, para asegurar la correcta implementación y coordinación territorial, se prevé la continuidad del grupo de trabajo interautonómico de economía circular ${ }^{17}$, formado por representantes de las Comunidades Autónomas, de la Federación Española de Municipios y Provincias y el MAPAMA.

\section{g) Mecanismos e indicadores de seguimiento y de evaluación}

El principal mecanismo de evaluación consistirá en la elaboración con carácter cuatrienal de un informe de resultados, efectos e impactos, que servirá a su vez para la actualización del Plan de Acción. Se han seleccionado 17 indicadores que, a partir de los datos suministrados por el INE y Eurostat, permitirán evaluar los siguientes ámbitos: producción y consumo; gestión de residuos; materias primas secundarias; reparación, reutilización y reciclado; impuestos; empleo; e $\mathrm{I}+\mathrm{D}+\mathrm{i}$.

Entre los indicadores propuestos para el seguimiento de la EEEC, se encuentran el Consumo Nacional de Materiales; la productividad de materiales y energética, las tasas de reciclaje y vertido de residuos; el comercio de materias primas secundarias; el gasto por hogar en reparación y alquiler de prendas de vestir y aparatos domésticos; el volumen de agua reutilizada; la ratio de impuestos ambientales sobre el total de impuestos; el empleo en economía circular; el porcentaje de empresas que innovan por "motivos circulares"; la inversión privada en los sectores del reciclaje, reparación y reutilización; o el número de patentes relacionadas con el reciclaje de materias primas secundarias.

El anterior catálogo de indicadores configura un cuadro de seguimiento que, en sintonía con otros elementos de la EEEC, no concede la importancia debida a la fase de diseño de los productos como mecanismo de prevención de residuos. A

\footnotetext{
${ }^{16}$ En el momento de presentación del documento, formaban parte de la Comisión los Ministerios de Hacienda y Función Pública, Interior, Fomento, Empleo y Seguridad Social, Energía, Turismo y Agenda Digital, Agricultura y Pesca, Alimentación y Medio Ambiente, Presidencia y para las Administraciones Territoriales, Economía, Industria y Competitividad, Sanidad, y Servicios Sociales e Igualdad, además de la Oficina Económica del Presidente del Gobierno.

17 Este grupo fue constituido en el seno de la comisión de Coordinación de residuos del MAPAMA, habiendo participado ya en la redacción de la EEEC.
} 
lo anterior se suman otros factores igualmente negativos, como la dificultad para valorar adecuadamente algunas magnitudes de carácter demasiado general o de difícil concreción - gasto en protección ambiental, empleo en economía circular, empresas que innovan por "motivos circulares" - o la inclusión de mecanismos de seguimiento sobre cuestiones que no contemplan actuaciones concretas -las propuestas sobre fiscalidad ambiental brillan por su ausencia, por lo que sorprende la intención de mensurar este elemento-.

\section{Plan de acción 2018-2020}

La segunda parte del documento propone un catálogo de 70 medidas para el primer subperíodo de aplicación, 2018-2020, que se ordenan en los ochos ejes estratégicos y cuentan con un presupuesto de más de 836 millones de euros, si bien la mayor parte de esa cuantía va destinada exclusivamente a los ejes de reutilización del agua $(57,15 \%)$ e I+D+i $(28,81 \%)$. Por otra parte, el remanente asignado a los ejes de producción y consumo tiene como partidas más substanciosas la reconversión de destinos turísticos y el desarrollo de una estrategia de la Secretaría de Estado de Turismo 2018-2020, actuaciones de cuestionable conexión con la economía circular.

Además, el Plan de Acción concentra la totalidad de sus propuestas de revisión legislativa en la obligada transposición de Directivas europeas sobre residuos, ignora la virtualidad de instrumentos propios del Derecho Público que están llamados a ser piezas clave en materia de circularidad -incentivos fiscales, contratación pública verde- - y no incluye ningún tipo de regulación para combatir la obsolescencia programada. La mayor parte de las medidas presentan un contenido impreciso, echándose de menos objetivos ambiciosos a la vez que accesibles en el trienio de aplicación, indicadores que faciliten la evaluación y una articulación consistente que muestre la contribución efectiva de cada medida al cambio de modelo.

Para ilustrar la deficiente articulación de algunas medidas, sin prejuicio de ulteriores análisis más profundos, nos podemos referir a la producción ecológica de alimentos, que se revela como un sector clave para la estrategia europea de economía circular. No en vano, entre las reformas legislativas en materia de 
economía circular aprobadas por el Parlamento y el Consejo el 30 de mayo de 2018, se incluye el nuevo Reglamento sobre producción ecológica y etiquetado de los productos ecológicos de la UE.

En el borrador de la EEEC, la medida núm. 10 promete el apoyo a este tipo de producción, atribuyendo la responsabilidad de su implementación a la DG de la Industria Alimentaria, si bien no se contempla una partida presupuestaria para su impulso. Se realiza una remisión a la Estrategia para la Producción Ecológica 2018-2020 publicada por el MAPAMA en febrero de 2018, que tampoco incluye partidas para actuaciones concretas, circunstancia que se justifica del siguiente modo: "los modelos de líneas estratégicas, a diferencia de los Planes de Acción, no suelen prefijar partidas fijas a actuaciones concretas. En esta característica reside la mayor flexibilidad y rapidez de adaptación y respuesta de las primeras frente a los segundos, factor de gran importancia para afrontar los cambios esperables en un sector muy dinámico e inmerso en un proceso de profunda reforma normativa" (MAPAMA, 2018: 61). La implementación de la estrategia, aún carente de presupuesto, está previsto que se realice a través de "una revisión de cuantas actividades se gestionan en las distintas unidades que componen el variado organigrama del Departamento" (MAPAMA, 2018: 61), funcionando por tanto los objetivos y líneas estratégicas establecidas a modo de principios ordenadores de las actuaciones de los departamentos y organismos involucrados.

Además, sorprende la débil conexión que presenta la EEEC entre producción ecológica y políticas circulares, reconociendo que serán necesarios ulteriores estudios que ofrezcan certezas sobre cuál será la contribución de la producción ecológica al avance hacia la circularidad. En este sentido, la EEEC recoge los objetivos de la Estrategia para la Producción Ecológica, entre los que se encuentra "[e]studiar el papel de la producción ecológica en la política de medio ambiente y adaptación al cambio climático", señalando que "[l]a coherencia de la agricultura y ganadería ecológicas con la política medioambiental podría encontrarse en su contribución a la sostenibilidad del sistema agroalimentario. Resultando, por tanto, interesante desarrollar estudios detallados sobre esta materia" (MAPAMA, 2018: 24). Sin duda es necesario acumular conocimiento sobre los factores que dificultan el cambio de modelo: este primer diagnóstico es 
la base sobre la que se desarrollar políticas e instrumentos que conviertan en realidades las bienintencionadas declaraciones de compromiso. Ahora bien, de poco sirve elaborar informes si no se echa mano de instrumentos jurídicos y financieros que reviertan la problemática estudiada e impulsen la transición hacia una economía más circular.

\section{NOTAS CARACTERÍSTICAS DE LA ESTRATEGIA}

Una vez perfilada de manera general la EEEC, interesa abordar una serie de tendencias que recorren el documento $y$, a nuestro juicio, son elocuentes sobre el carácter poco ambicioso de la estrategia y la posición débil que quiere ocupar España en la transición hacia la circularidad. Más que un estudio pormenorizado de las acciones propuestas, tarea que merecería sucesivas monografías sectoriales, hemos decidido destacar cinco notas características que, por su relevancia e implicaciones sobre los diferentes sectores y ejes de actuación, explican el desinterés o falta de iniciativa que ha mostrado el Gobierno del Estado por la economía circular.

En particular, nos parecen significativas las siguientes notas características de la estrategia: unas reformas concentradas de modo exclusivo en el sector residuos ( $v$. infra apartados 1 y 2 ); una renuncia a utilizar los instrumentos fiscales para incentivar las prácticas circulares ( $v$. infra apartado 3 ); y un desplazamiento de poderes de decisión típicos del sector público (v. infra apartado 4).

\section{Reformas concentradas exclusivamente en el sector residuos}

El nuevo paquete de directivas aprobado recientemente por el Parlamento y el Consejo, a propuesta de la Comisión, ha modificado el grueso de la normativa europea sobre la materia -Directivas de residuos, vertederos, envases, vehículos al final de su vida útil, pilas y acumuladores, y residuos de aparatos eléctricos y electrónicos-. Por tanto, España deberá "adaptar progresivamente su legislación para cumplir con los nuevos objetivos e incorporar las nuevas directrices normativas aprobadas por el legislador europeo" (MAPAMA y 
MINEICO, 2018: 101), fijándose la fecha límite para la transposición de las cuatro directivas en el 5 de julio de 2020.

En consecuencia, también será sometido a revisión el paquete de normas que hoy constituye el tronco de la legislación española de residuos: Ley 22/2011, de 29 de julio, de residuos y suelos contaminados; Ley 11/1997, de 24 de abril, de envases y residuos de envase; Real Decreto 1481/2001, de 27 de diciembre, de eliminación de residuos en vertedero; Real Decreto 679/2006, de 2 de junio, de la gestión de los aceites industriales usados; Real Decreto 106/2008, de 1 de febrero, sobre pilas y acumuladores y la gestión ambiental de sus residuos; Real Decreto 1310/1990, de 29 de octubre, por el que se regula la utilización de los lodos de depuración en el sector agrario; Real Decreto 1619/2005, de 30 de diciembre, sobre la gestión de neumáticos fuera de uso; y Real Decreto 105/2008, de 1 de febrero, por el que se regula la producción y gestión de los residuos de construcción y demolición.

Este paquete de reformas sobre residuos merece al menos dos comentarios. En primer lugar, cabe cuestionar el carácter innovador de las propias revisiones introducidas por el legislador europeo, que deben ser interpretadas a la luz de la reflexión introducida por SANTAMARÍA ARINAS (2016: 36) con ocasión de la publicación del paquete de reformas propuesto por la Comisión en diciembre de 2015: "para calibrar adecuadamente el alcance de las innovaciones que estos documentos proponen, conviene empezar recordando que, tras la ya larga evolución experimentada por la política europea en materia de residuos, las bases del sistema están consolidadas desde hace 25 años". El mismo autor se mostraba crítico con una reforma que, en términos generales, "viene a acentuar el característico conceptualismo de la regulación (como si con nombrar expresamente los problemas éstos se solucionaran); a actualizar, con retraso, compromisos previos en materia de prevención (donde, por cierto, los verdaderos avances habrá que seguir buscándolos fuera del sector normativo de los residuos) y a centrar principalmente la atención en dos frentes bien conocidos de la gestión" (SANTAMARÍA ARINAS, 2016: 43).

En segundo lugar, también es cuestionable que todas las reformas se concentren en el sector de los residuos, eludiendo avanzar en el ámbito de la prevención desde otros sectores del ordenamiento. Como decíamos al inicio de este trabajo 
(v. supra apartado II.3), las mayores oportunidades para reducir la cantidad de residuos generados residen en aquellas políticas que atajan el problema de raíz, esto es, que actúan sobre las fases de producción y diseño. En este sentido se manifestaba el propio Plan de Acción de la UE cuando afirmaba que las reformas legislativas sobre residuos debieran servir como un impulso para la utilización de instrumentos económicos y otras herramientas, con el fin de garantizar en el cumplimiento de la jerarquía de residuos, señalando que "es esencial ofrecer incentivos para la mejora del diseño de los productos" (CE, 2015: 4). Este es, además, el aspecto realmente novedoso de la economía circular. Por este motivo, inquieta que la EEEC reserve un papel irrelevante para aquellas políticas que podrían movilizar a los actores económicos en la dirección de la economía circular desde las fases iniciales de la cadena productiva. Nos referimos, por ejemplo, a las medidas de carácter fiscal (v. infra apartado 3) o de promoción del diseño ecológico de los productos (v. infra apartado 2.b).

\section{Las implicaciones de la estrategia más allá del sector residuos}

A continuación, abordaremos las reformas planteadas en tres sectores clave: los plásticos, los aparatos eléctricos y electrónicos y la construcción. Estos sectores son paradigmáticos para la estrategia de economía circular, tanto por el elevado consumo de materiales que suponen como por las posibilidades de mejora de los actuales modelos de planificación, uso de los recursos, prevención y gestión de residuos. Por este motivo -a falta de un análisis más profundo de las reformas que requiere cada ámbito de actuación, tarea que excede el objeto de este trabajo-, consideramos que el examen de las medidas planteadas por la EEEC para los sectores citados puede aportar luz sobre el grado de ambición, la capacidad para responder a los cambios exigidos y la adecuación a la estrategia europea de economía circular, entre otros extremos. 


\section{a) Plásticos: impasibilidad ante la nueva estrategia europea}

Otra de las novedades previstas en la EEEC es la incorporación al ordenamiento español de las especificaciones de la reciente Estrategia europea de plásticos ${ }^{18}$ (EEP), que ha aprobado recientemente la Comisión Europea para alertar sobre el despilfarro de este material. Según este documento, actualmente se generan en Europa unos 25,8 millones de toneladas de residuos de plástico al año, reciclándose menos del $30 \%$ de esa cantidad. Además, buena parte de este porcentaje es trasladada a terceros países con una normativa ambiental menos exigente, dificultando su recuperabilidad y trazabilidad. El resto de los plásticos desechados se acumulan en vertederos (31\%) o son incinerados (39\%).

Para revertir esta situación, la Comisión propone unos objetivos ambiciosos para el año 2030, fecha en la que todos los envases de plástico comercializados en la Unión deberán ser reutilizables o poder reciclarse de un modo rentable; más de la mitad de los residuos de plásticos deberán ser reciclados; y la capacidad de selección y reciclado deberá cuadriplicarse con respecto a los niveles de 2015. Estos objetivos tienen en cuenta las diferencias existentes entre la capacidad de reciclaje de los distintos Estados miembros, siendo en principio asumibles por todos ellos, pero no impiden que aquellos países más aventajados implanten objetivos más ambiciosos. En este sentido, la Hoja de ruta francesa para la economía circular ${ }^{19}$ propone alcanzar un $100 \%$ de plásticos reciclados en 2025.

Por su parte, el borrador de la estrategia española apenas dedica un par de líneas a la materia, limitándose a encomendar al MAPAMA la incorporación de la EEP al ordenamiento nacional. Consideramos que la elaboración de una estrategia nacional de economía circular constituye una buena oportunidad para abordar la problemática de forma integral y coordinada, en atención también al papel central que ocupan los plásticos en la prevención y gestión de residuos, motivo por el que el comité de elaboración de la EEEC debería tratar de integrar el contenido de la EEP. Habrá que esperar a la publicación del texto definitivo

\footnotetext{
$18<$ https://eur-lex.europa.eu/legal-content/ES/TXT/?uri=COM\%3A2018\%3A28\%3AFIN> [Última consulta: 12.10 .2018$]$

${ }^{19}$ La feuille de route pour l'économie circulaire (FREC) se puede consultar en la web del Ministère de la Transition écologique et solidaire: <https://www.ecologique-solidaire.gouv.fr/feuille-routeeconomie-circulaire-frec> [Última consulta: 10.10.2018].
} 
para comprobar si introduce alguna novedad al respecto y conocer en qué términos se produce la incorporación.

b) Aparatos eléctricos y electrónicos: el reto de la obsolescencia programada

El Plan de acción sobre economía circular de la UE destaca la importancia de los productos eléctricos y electrónicos en este contexto, añadiendo que "[h]asta la fecha, los requisitos de diseño ecológico se han orientado hacia la eficiencia energética; en el futuro, se examinarán sistemáticamente cuestiones tales como la reparabilidad, la durabilidad, la posibilidad de actualización, la reciclabilidad o la identificación de determinados materiales o sustancias" (CE, 2015: 4). La Comisión también alertaba en el mismo documento sobre una cuestión que afecta especialmente al sector de los aparatos eléctricos y electrónicos (AEE), menoscabando la durabilidad de los productos: la obsolescencia programada.

En esta misma línea se sitúa el plan de trabajo en materia de ecodiseño para el período 2016-201920, que propone aplicar los principios de la economía circular en el diseño de AEE. Mientras que hasta el momento se han invertido grandes esfuerzos en mejorar la eficiencia energética de los productos - al amparo de la Directiva 2009/125/CE ${ }^{21}$, por la que se instaura un marco para el establecimiento de requisitos de diseño ecológico aplicables a los productos relacionados con la energía-, el nuevo objetivo consiste en aumentar la contribución del sector a la economía circular, optimizando la vida útil de los aparatos y sus componentes y mejorando su durabilidad, resistencia y capacidad de reparación o reutilización.

Más recientemente, el Parlamento Europeo ha publicado el Informe sobre una vida útil más larga para los productos: ventajas para los consumidores y las empresas, de 9 de junio 2017, en el que solicita a la Comisión y a los Estados miembros que tomen medidas efectivas para garantizar los siguientes objetivos: el diseño de productos sólidos, sostenibles y de calidad; las posibilidades de reparación y de alargamiento de la vida útil; la aplicación de modelos de negocio

20 <https://ec.europa.eu/energy/sites/ener/files/documents/com_2016_773.en_.pdf> [Última consulta: 12.10 .2018$]$.

21 Directiva 2009/125/CE del Parlamento Europeo y del Consejo, de 21 de octubre de 2009, por la que se instaura un marco para el establecimiento de requisitos de diseño ecológico aplicables a los productos relacionados con la energía. <https://www.boe.es/doue/2009/285/L0001000035.pdf> [Última consulta: 12.10.2018]. 
orientados al uso de los productos - "producto como servicio"-; la aplicación de la jerarquía de residuos; una mejor información al consumidor; la persecución de la obsolescencia programada; o garantizar el derecho a la garantía legal de conformidad. El informe, elaborado por la Comisión de Mercado Interior y Protección del Consumidor, también incluye una lista de medidas que podrían ser implementadas para alcanzar estos objetivos.

Por último, entre las novedades introducidas por el paquete de economía circular aprobado recientemente por el Parlamento y el Consejo se encuentra la Directiva (UE) 2018/849, de 30 de mayo de $2018^{22}$, que entre otras modifica la Directiva 2012/19/UE sobre RAEE. El nuevo art. 16 bis introducido en esta última Directiva anima a los Estados miembros a establecer incentivos económicos para cumplir con el principio de jerarquía de residuos y alcanzar los objetivos propuestos.

Sin embargo, a pesar de las recomendaciones de las instituciones europeas, en el borrador de la EEEC se renuncia a ocupar una posición de vanguardia en materia de ecodiseño de AEE y lucha contra la obsolescencia programada, encontrando apenas un par de referencias en clave de diagnóstico a este tipo de prácticas fraudulentas. Se menciona la obsolescencia programada como una causa de reducción de la vida útil de los bienes de consumo, aunque menos frecuente e importante que otras como el cambio de preferencias de los consumidores, que prefieren comprar aparatos nuevos, y la obsolescencia técnica, que se define como la incompatibilidad con nuevos software 0 tecnologías. En última instancia, "en algunos casos", se pueden detectar prácticas de obsolescencia programada. Por su parte, el plan de acción para el período 2018-2020 incluye una única referencia, advirtiendo que "será necesario evitar prácticas de obsolescencia programada o prematura" en la medida en que menoscaban la confianza de los consumidores, indispensable para que "se decidan a pagar un poco más por productos que ofrecen mejores características de calidad y durabilidad" (MAPAMA y MINEICO, 2018: 90).

\footnotetext{
22 Directiva (UE) 2018/849 del Parlamento Europeo y del Consejo, de 30 de mayo de 2018, por la que se modifican la Directiva 2000/53/CE relativa a los vehículos al final de su vida útil, la Directiva 2006/66/CE relativa a las pilas y acumuladores y a los residuos de pilas y acumuladores y la Directiva 2012/19/UE sobre residuos de aparatos eléctricos y electrónicos. Esta directiva forma parte del "paquete para la economía circular" propuesto por la Comisión Europea en diciembre $\quad 2015.2$ de 2 https://eur-lex.europa.eu/legalcontent/ES/TXT/?uri=CELEX\%3A32018L0849> [Última consulta: 15.10.2018].
} 
Resulta interesante un examen comparado de las iniciativas que han aprobado nuestros vecinos franceses en los últimos años para vislumbrar los pasos que se pueden dar en materia de lucha contra la obsolescencia programada. Ya en agosto de 2015, como preludio de la Cumbre climática de París, fue aprobada la Ley 2015-992, de 17 de agosto de 2015, relativa a la Transición Energética para el Crecimiento Verde, que incorporó la penalización de la obsolescencia programada de los productos de consumo, definida como el conjunto por las cuales un comercializador busca reducir deliberadamente el ciclo de vida de un producto para aumentar su tasa de remplazamiento ${ }^{23}$. La norma modificó el Código de Consumo francés ${ }^{24}$, que tras la reforma prevé multas de hasta 300.000 euros y dos años de cárcel. Recientemente los medios de comunicación se han hecho eco de las investigaciones de la Fiscalía francesa a las multinacionales Epson y Apple, en este último caso por prácticas fraudulentas consistentes en la manipulación de las baterías de sus teléfonos móviles más antiguos a través de actualizaciones que reducirían su rendimiento y su duración con el fin de acelerar su reemplazo.

En esta línea parece continuar la hoja de ruta francesa para la economía circular, presentada el 2 de mayo de 201825. La estrategia francesa advierte que el cambio de modelo no se producirá espontáneamente, sino que requiere de la iniciativa estatal para definir un cuadro económico y financiero que incite a los actores a tomar decisiones en el sentido de la economía circular. A este fin, entre otras medidas, propone movilizar los instrumentos propios de la fiscalidad verde e implementar una etiqueta sobre el ciclo de vida de los productos que los puntúe según criterios de ecodiseño, durabilidad o reparabilidad. Esta etiqueta debería ser adoptada antes del 1 de enero de 2020 y su uso sería voluntario, si bien el Gobierno francés ha manifestado su intención de presionar en el seno de las instituciones europeas para aprobarla de forma obligatoria a escala europea. De forma más general, la hoja de ruta señala que se actuará para llevar el modelo

23 Actualmente, art. L441-2 del Código de consumo, tras la modificación operada por la Ordenanza núm. 2016-301, de 14 de marzo de 2016.

${ }^{24}$ Art. L213-4-1 del Código de consumo.

${ }^{25}$ La feuille de route pour l'économie circulaire (FREC) se puede consultar en la web del Ministère de la Transition écologique et solidaire: <https://www.ecologique-solidaire.gouv.fr/feuille-routeeconomie-circulaire-frec> [Última consulta: 10.10.2018]. 
de economía $100 \%$ circular al nivel europeo e internacional a través de la iniciativa \#MakeOurPlanetGreatAgain y que, tras los pasos del liderazgo que ha tomado en materia climática, Francia quiere convertirse en la punta de lanza de la economía circular a nivel mundial.

c) Sector de la construcción: ¿sólo residuos?

Otro sector que aborda la EEEC es el de la construcción, si bien consideramos que lo hace con un enfoque demasiado centrado en la reutilización de los residuos de construcción y demolición (RCD). Esta cuestión, que no deja de ser una exigencia de la vigente normativa sobre residuos, parece resolverse con una mayor aplicación de la propia normativa. Sin embargo, una perspectiva verdaderamente ambiciosa de la transformación planteada por la estrategia de economía circular debiera incidir sobre el propio modelo de urbanismo y edificación, teniendo en cuenta las siguientes consideraciones.

A priori, parece que un modelo urbanístico basado en el consumo expansivo de suelo en la periferia urbana no camina en la dirección de la circularidad, de la misma manera que tampoco parece sostenible una turistificación masiva de los centros de las ciudades que implique el desplazamiento de importantes masas de población hacia la periferia. Estas dinámicas ocasionan un incremento del suelo edificado y un mayor consumo de recursos en la construcción de edificios, vías de comunicación o transporte, oponiéndose frontalmente a los presupuestos de la economía circular. En cambio, estrategias de planificación urbana basadas en la rehabilitación del parque inmobiliario ruinoso, activación de los inmuebles vacíos en manos de grandes propietarios, recuperación de zonas degradadas, densificación de los núcleos urbanos y creación de redes de transporte público que aseguren la conexión, entre otras propuestas, podrían aportar beneficios evidentes en materia de economía circular y uso racional de los recursos.

La relación entre el concepto de economía circular y el urbanismo ya ha sido abordada por algunos autores. Es el caso de BUSTILLO BOLADO (2018: 112 y ss.), que hace explícita la conexión a través del concepto de ecosistema urbano: "trabajar en la planificación y ordenación urbanística, territorial y ambiental tomando como punto de partida el modelo de ecosistema urbano (que no deja 
de ser una relevante plasmación territorial del moderno concepto -como tendencia- de economía circular) facilita efectuar análisis y tomar decisiones tendentes a reducir el impacto negativo en la interrelación de la ciudad con los ecosistemas naturales y rurales".

Nos encontramos ante una visión más amplia de la economía circular como principio ordenador de las políticas urbanas. En aplicación de este, se deberían tener en cuenta las externalidades negativas que los planes urbanísticos puedan proyectar sobre el medio, con el fin de eliminar todo consumo de recursos innecesario o ineficiente. Una concepción circular de la edificación debiera considerar este tipo de criterios en el proceso de toma de decisiones, especialmente para aquellos proyectos que supongan una expansión del suelo construido, en la concesión de licencias para nuevas edificaciones o en la aprobación de estrategias de rehabilitación del parque inmobiliario existente. Por este motivo, consideramos que una aplicación de la economía circular centrada exclusivamente en los residuos de obra, como la que defiende el borrador de la EEEC no representa una visión novedosa ni un "cambio sistémico" en el uso de los recursos. Gestionar adecuadamente los RCD, a través de la valorización y reutilización en otras obras, no es más que un parche ante un problema que requiere soluciones más ambiciosas. En este sentido, las mayores posibilidades de acabar con el despilfarro de recursos pasan por estrategias de planificación urbana que aborden el problema desde su raíz, es decir, que tengan en cuenta el consumo de recursos -entre ellos, el suelo- y la interacción con el medio natural a la hora de diseñar o planificar la ciudad.

\section{Fiscalidad ambiental: entre la armonización y la falta de incentivos}

La fiscalidad ambiental es un instrumento clave para la puesta en marcha de la estrategia de economía circular, por sus posibilidades para orientar el consumo hacia un cierto tipo de productos más circulares en detrimento de otros que suponen un mayor despilfarro de recursos. Así lo contempla el Plan de Acción de la UE, que señala como objetivo de la estrategia "garantizar que se disponga del marco normativo adecuado para el desarrollo de la economía circular en el mercado único, y transmitir señales claras a los operadores económicos y a la sociedad en general sobre el camino que ha de seguirse" (CE, 2015: 2), para 
más adelante añadir que "[e]l precio es un factor clave que afecta a las decisiones de compra, tanto en la cadena de valor como para los consumidores finales. Por lo tanto, se alienta a los Estados miembros a ofrecer incentivos y a usar instrumentos económicos como, por ejemplo, la fiscalidad para garantizar que los precios reflejen mejor los costes ambientales de los productos" (CE, 2015: 7).

Parece claro que los planes de la Comisión en materia de economía circular incluían un papel activo de los Estados miembros en materia de fiscalidad, animando a utilizar los instrumentos tributarios para impulsar la transición. Sin embargo, la EEEC no parece recoger el testigo entregado por las instituciones europeas y, como en tantos otros ámbitos, se limita a remitirse de forma vaga e imprecisa a los instrumentos existentes. En el ámbito de la fiscalidad ambiental, el plan de acción de la estrategia española se ceñirá a realizar "un análisis sobre fiscalidad medioambiental en España con objeto de plantear las líneas a seguir en un futuro" - medida núm. 26 del Plan de Acción 2018-2020-. Como vemos, el recurso al estudio y análisis de las mejores opciones disponibles para una futura puesta en marcha es una constante en el documento.

Es relevante que, como sucede en otros sectores, se anuncia un "estudio sobre la posible armonización de los distintos impuestos autonómicos en materia de residuos en España" - medida núm. 25-que hay que entender en el marco de un proceso más amplio de recentralización en el sistema de financiación y de limitación de la autonomía financiera autonómica y local. La autonomía financiera de las comunidades autónomas ha sido menoscabada por la última jurisprudencia constitucional, deterioro que ha ido de la mano de un abandono de la protección ambiental como finalidad extrafiscal ${ }^{26}$. El Tribunal Constitucional ha declarado la nulidad de diversos tributos autonómicos con base en la prohibición de duplicidades con los tributos estatales y locales impuesta por los apartados 2 y 3 del art. 6 LOFCA ${ }^{27}$, afirmando que existía una equivalencia entre

\footnotetext{
${ }^{26}$ Sirvan como ejemplos las sentencias del Tribunal Constitucional 74/2016, de 20 de mayo, que declaró la nulidad del impuesto sobre la producción de energía eléctrica de origen nuclear de la Ley del Parlamento de Cataluña 12/2014, de 10 de octubre, o las sentencias 196/2012, de 31 de octubre, y 60/2013, de 13 de marzo, que declararon la nulidad de los impuestos a la producción termonuclear de electricidad y de almacenamiento de residuos nucleares en las Leyes de las Cortes de Castilla-La Mancha 11/2000, de 26 de diciembre, y 16/2005, de 29 de diciembre, respectivamente.

27 Artículo 6 LOFCA:
} 
los elementos esenciales de los tributos aprobados por varios Parlamentos regionales y tributos estatales ya existentes. Cabe destacar que esta jurisprudencia se basa en un mero análisis formal y acrítico de los elementos esenciales del tributo — base, tipo y hecho imponible-, ignorando la finalidad extrafiscal ambiental de los tributos autonómicos anulados que vendría a otorgar una mayor protección al medio ambiente, como ha sido criticado por el magistrado Xiol Ríos en varios votos particulares ${ }^{28}$. En el voto particular emitido en la STC 74/2016, el magistrado señala que "la interpretación del art. 6.2 LOFCA y el control de constitucionalidad que deriva del mismo debe hacerse atendiendo de manera principal al espíritu de respeto a la autonomía financiera que el poder constituyente otorgó a las comunidades autónomas" y que "la sensibilidad mostrada por la jurisprudencia constitucional hacia la utilización de instrumentos tributarios en el cumplimiento de esa finalidad de protección medioambiental ha sido escasa [...]. El análisis de los diferentes pronunciamientos del Tribunal cuando se han planteado cuestiones relativas a

Uno. Las Comunidades Autónomas podrán establecer y exigir sus propios tributos de acuerdo con la Constitución y las Leyes.

Dos. Los tributos que establezcan las Comunidades Autónomas no podrán recaer sobre hechos imponibles gravados por el Estado. Cuando el Estado, en el ejercicio de su potestad tributaria originaria establezca tributos sobre hechos imponibles gravados por las Comunidades Autónomas, que supongan a éstas una disminución de ingresos, instrumentará las medidas de compensación o coordinación adecuadas en favor de las mismas.

Tres. Los tributos que establezcan las Comunidades Autónomas no podrán recaer sobre hechos imponibles gravados por los tributos locales. Las Comunidades Autónomas podrán establecer y gestionar tributos sobre las materias que la legislación de Régimen Local reserve a las Corporaciones locales. En todo caso, deberán establecerse las medidas de compensación o coordinación adecuadas a favor de aquellas Corporaciones, de modo que los ingresos de tales Corporaciones Locales no se vean mermados ni reducidos tampoco en sus posibilidades de crecimiento futuro.

${ }^{28}$ En el voto particular emitido en la STC 74/2016, de 20 de mayo, que declaró la nulidad del impuesto sobre la producción de energía eléctrica de origen nuclear de la Ley del Parlamento de Cataluña 12/2014, de 10 de octubre, el magistrado Xiol Ríos afirma que "[m]i discrepancia con este razonamiento radica en que (i) el análisis que debe proyectarse sobre este tipo de supuestos no puede ser tan pretendidamente mecánico como para limitarse a una mera confrontación de hechos imponibles. Desde una perspectiva constitucional, resulta necesario trascender a otros elementos que forman parte esencial de la configuración de la organización territorial del Estado diseñada en el título VIII de la Constitución. Además, (ii) no puedo compartir las reticencias respecto de la plena asunción de la protección medioambiental como una finalidad extrafiscal constitucionalmente legítima y de primera magnitud en la configuración del poder tributario autonómico. En relación con ello, (iii) no aprecio esa supuesta identidad formal y material entre los elementos del tributo estatal, que se ha establecido como elemento de comparación, y el autonómico objeto de impugnación, habida cuenta de la primordial finalidad extrafiscal de protección medioambiental del tributo autonómico que aparece reflejada en sus elementos estructurales." 
impuestos autonómicos con finalidades extrafiscales medioambientales evidencia, a mi juicio, esa falta de sensibilidad".

La interpretación restrictiva del art. 6 LOFCA que adopta la última jurisprudencia constitucional puede haber limitado la potestad de las comunidades autónomas para imponer una mayor protección ambiental a través de instrumentos tributarios, ignorando la finalidad ambiental de éstos como un elemento esencial. Consideramos que esta situación, dicho sea con las cautelas propias de quien no es especialista en la materia, hace necesaria una revisión del sistema fiscal que ponga en valor la finalidad extrafiscal ambiental de los tributos, pues no es posible concebir un avance hacia modelos más circulares y sostenibles que venga acompañado de un retroceso en protección ambiental.

\section{Un desplazamiento del poder de decisión del sector público}

En la estrategia de economía circular, como en tantas otras normas que han sido aprobadas en las últimas décadas, observamos una dejación de funciones o un desplazamiento del poder de regulación típico del sector público sobre asuntos que, por afectar a cuestiones esenciales como la protección del medio ambiente - la salud pública, deberían ser decididos por las instancias políticas que representan la voluntad ciudadana. En la EEEC también podemos encontrar esta tendencia y comprobar cómo la toma de decisiones se desplaza en una doble dirección: por una parte, hacia la tecnología y el ámbito científico, a través de las denominadas cláusulas de remisión técnica, y, por otra parte, hacia el sector privado.

En primer lugar, la EEEC deposita una confianza ilimitada en la tecnología y la transformación digital, como si por ella misma fuese a traer consigo un aumento de la eficiencia en el uso de los recursos, la descarbonización de la economía o la reducción de la dependencia de las materias primas. Un buen ejemplo lo encontramos en uno de los sectores prioritarios para la estrategia, la industria, en el que toma protagonismo la denominada cuarta revolución industrial, basada en la introducción y fomento de las tecnologías y la transformación digital en el seno de las empresas industriales. De lo escrito en el documento se desprende que la transformación digital reportará grandes beneficios pues, según se afirma 
en el documento, "contribuye a aumentar la flexibilidad del proceso productivo y la eficiencia en el uso de recursos como el espacio, la energía, las materias primas o el tiempo por ejemplo" (MAPAMA y MINEICO, 2018: 45). Así, entre las iniciativas más destacadas se encuentra la de Industria Conectada 4.0, que tiene como lema "la transformación digital de la industria española" y, como objetivo, "que el tejido industrial español se beneficie del uso intensivo de las tecnologías de la información y de las comunicaciones en sus procesos productivos y en todos los ámbitos de su actividad. Para ello es necesario introducir y fomentar el uso intensivo de las tecnologías en las empresas. Tecnologías como son, por ejemplo, la computación en la nube, el big data, la impresión 3D, la robótica colaborativa, la realidad aumentada, los sistemas ciberfísicos o el internet de las cosas" (MAPAMA y MINEICO, 2018: 45).

En estos párrafos se advierte un uso excesivo de la denominada cláusula técnica o de remisión a la tecnología, sobre la que ESTEVE PARDO (2015: 38) señala que "se contiene ya en casi todas las decisiones de la Administración Pública que se adoptan en sectores en los que el elemento tecnológico tiene una posición relevante, que son muchos, y de gran importancia y futuro: desde la tecnología y las telecomunicaciones hasta el medio ambiente". Esta remisión constante a la mejor tecnología posible implica una ausencia de regulación o decisión sobre el componente tecnológico por parte del Estado, que ante el desconocimiento o la incertidumbre científica se somete o subordina a las disposiciones de la ciencia, confirmando la "tendencia del Derecho, del Derecho Público —que es el Derecho de la decisión y la regulación por parte de las autoridades públicas-, a entregarse a los dictados de las disciplinas que puedan conocer sobre la materia que se trate" (ESTEVE PARDO, 2015: 38) ${ }^{29}$, ante los que este autor hace un llamamiento a reconstruir un ámbito de toma de decisiones desde el Derecho que integre el conocimiento.

Por otra parte, también se observa en la EEEC un desplazamiento de funciones de decisión típicamente públicas hacia el sector privado, depositándose excesiva confianza en las decisiones que adopten las empresas industriales con respecto

${ }^{29}$ Esteve Pardo señalaba en El desconcierto del Leviatán (2009: 95) que "[e]l derecho ha venido mostrando una rendida reverencia, primero a los descubrimientos científicos y luego al progreso tecnológico, que le ha llevado a asumir sin capacidad de crítica y decisión propia, las propuestas y soluciones del mundo de la ciencia y la tecnología". 
al componente tecnológico. No se advierte la mínima intención de regular los avances científicos en el sector para orientarlos hacia la consecución de los fines perseguidos por el sector público y el interés general, sino que se espera que las transformaciones tecnológicas y digitales seleccionadas por los propios agentes económicos traerán por sí mismas el cambio hacia la circularidad. Esta postura podría ser calificada cuanto menos de inocente, pues no se puede obviar que los fines o intereses que persigue el sector privado son esencialmente privados, esto es, la obtención y maximización de beneficios económicos, y parece seguir la dinámica de "desregulación ambiental escondido bajo la bandera de la buena regulación con una orientación neoliberal" a la que se refiere NOGUEIRA LÓPEZ (2018: 41).

Otra forma de expansión de lo privado es la constante remisión a organizaciones representativas de la técnica, sometidas al Derecho privado, para que asuman funciones de regulación ${ }^{30}$. Es el caso del Comité Europeo de Normalización (CEN) y el Comité Europeo de Normalización Electrotécnica (CENELEC), organizaciones privadas sin ánimo de lucro responsables de la estandarización europea de los productos, a las que la EEEC se remite para potenciar el ecodiseño de los productos y su "durabilidad, capacidad para la reparación, facilidad de reutilización, uso o reutilización de componentes, capacidad para refabricar, reciclabilidad, recuperabilidad, uso de materiales reciclados, uso de materias primas críticas y su reciclabilidad así como documentación y/o marcado de la información relacionada a la eficiencia de materiales del producto" (MAPAMA y MINEICO, 2015: 46). Sobre el papel de estos organismos, ESTEVE PARDO (2009: 103) señala que "[o]rganizaciones y empresas privadas, que ofrecen como principal activo el conocimiento experto del sector y su regulación técnica, configuran ese sistema desde el que se desarrollan funciones de control, acreditación y ejecución en el ámbito técnico, tradicionalmente ejercidas por las Administraciones Públicas y sobre las que ahora deciden en relevantes aspectos sujetos privados con la única legitimación de su conocimiento experto".

30 TARRÉS VIVES, M. desarrolla esta idea en "El papel de la normalización internacional en el contexto de la seguridad y el comercio de productos", en DARNACULLETA I GARDELLA, M. M., ESTEVE PARDO, J. y SPIECKER GEN. DÖHMANN, I. (eds.), Estrategias del Derecho ante la incertidumbre y la globalización, Marcial Pons, 2015, p. 137 y ss. 
La privatización de funciones públicas que acabamos de describir configura un panorama especialmente preocupante en materia ambiental, amenazando los estándares mínimos de protección y dejando en manos de grupos privados el bienestar de las generaciones futuras. Ante esta situación cabe traer a colación la reflexión que, desde la óptica de los derechos fundamentales, realiza DOMÉNECH PASCUAL (2006: 30): "los mayores peligros que hoy se ciernen sobre la libertad en las sociedades occidentales ya no provienen de los poderes públicos ni de la «naturaleza», sino de sujetos privados, de organizaciones cuyo poder en ocasiones supera en intensidad y extensión al de la mayoría de los Estados. Especialmente apremiante resulta protegerla frente a los inquietantes riesgos tecnológicos de una magnitud antes desconocida a los que todos o una buena parte de los ciudadanos quedamos expuestos". En atención a los nuevos peligros que describe, el autor llama al rearme del Derecho Público: "para que los poderes públicos lleven a término su nueva misión conviene remozar el arsenal jurídico disponible. Cada vez con más frecuencia se requiere de éstos no que se abstengan de interferir en las relaciones entre particulares, sino, al contrario, que intervengan a fin de garantizar la libertad de los más débiles. Ello exige establecer los mecanismos jurídicos adecuados para que las autoridades puedan acometer cabalmente esta tarea y para que los ciudadanos afectados puedan recabar y obtener su cumplimiento efectivo. Durante mucho tiempo el Derecho público se ha preocupado especialmente por poner límites y frenos a las intervenciones estatales. Ahora la necesidad es obligar al Estado a intervenir, garantizar que no permanezca inactivo frente a las nuevas amenazas para la libertad".

\section{CONCLUSIONES}

El borrador de la Estrategia Española para la Economía Circular no refleja el auténtico cambio de paradigma que prometían algunos de los documentos europeos y nos coloca en la cola de la transición hacia un modelo circular de producción y uso de los recursos. El retraso acumulado en la aprobación de la estrategia, su contenido poco innovador y su acusado carácter descriptivo demasiadas páginas describiendo el panorama actual para, en numerosos casos, acabar proponiendo sucesivos estudios en lugar de implementar políticas 
efectivas para la puesta en marcha de la estrategia- hacen pensar que el Gobierno español ha dedicado pocos esfuerzos a la elaboración del documento, limitándose a recoger las obligaciones de transposición de la normativa europea sobre residuos y a realizar menciones demasiado genéricas al resto de sectores. Resulta decepcionante que se ignoren las llamadas de la Comisión a utilizar los instrumentos económicos de los que se pueden servir los Estados miembros para incentivar la transición circular, prescindiendo de iniciativas interesantes en cuestión de fiscalidad ambiental, contratación pública ecológica o lucha contra la obsolescencia programada. El enfoque particularmente limitado que se observa en sectores como los plásticos, la construcción o los aparatos eléctricos y electrónicos redunda en el carácter poco novedoso y ambicioso del documento. Además, la EEEC deposita una confianza excesiva en la transformación tecnológico-digital y en la iniciativa de las empresas industriales para dirigir el cambio de modelo, rasgo que podemos enmarcar en la tendencia global de cesión de espacios de decisión públicos hacia el sector privado, sea hacia grupos empresariales o hacia agencias privadas de normalización que presentan el conocimiento experto como única fuente de legitimación.

En definitiva, la perspectiva reduccionista que se observa en algunos ámbitos de actuación —limitando la estrategia a una mejora del sistema de gestión de los residuos-, la renuncia a utilizar incentivos económicos y la cesión de espacios de decisión hacia el sector privado dan buena cuenta de la falta de interés por parte del Gobierno en acometer las reformas necesarias para avanzar hacia un uso más circular de los recursos. Con el fin de revertir esta tendencia negativa y salvar el retraso acumulado, el borrador de la EEEC debería ser sometido a una profunda revisión, dotando la estrategia de instrumentos normativos y financieros efectivos que devuelvan la iniciativa al sector público y sitúen a España en la senda de la circularidad. En este sentido, NOGUEIRA LÓPEZ (2018: 61) defiende que "[l]a economía circular —mucho más que una redenominación de la política de residuos - necesita de un apoyo sólido con medidas normativas, fiscales y organizativas que permitan desplegar todas sus potencialidades".

La publicación de instrumentos de soft law, como es el objeto de estudio en este trabajo, puede ser de utilidad para ciertos objetivos: integrar los diferentes retos, sectores e instrumentos en un mismo documento; planificar de forma integral y 
coordinada las acciones que se deben llevar a cabo; orientar el rumbo que deben tomar las propuestas de las diferentes Administraciones Públicas involucradas; y transmitir un rotundo mensaje de cambio al conjunto de la sociedad y, en particular, a los agentes económicos implicados —en el caso de la economía circular, con el objetivo añadido de mostrarles los sustanciosos beneficios económicos que puede reportar una estrategia de estas características-. Sin embargo, no podemos admitir que baste con publicar este tipo de documentos, con bienintencionadas declaraciones de compromiso, si no se acompañan de una serie de reformas y mecanismos que materialicen en resultados sus loables reflexiones.

Como en otros ámbitos de la política ambiental, es necesario un sector público que actúe de manera firme y responsable, dejando de lado intereses económicos cortoplacistas y emprendiendo de inmediato las reformas necesarias para hacer avanzar nuestra economía hacia un modelo circular de uso de los recursos. De lo contrario, el modelo lineal de producción y consumo que rige en sectores muy importantes de la economía española puede ocasionar un deterioro insalvable en materia ambiental, al tiempo que aumenta la dependencia de la extracción e importación de materias primas. La postergación de las reformas necesarias y la inacción de los poderes públicos nos situarán cada vez más lejos de la vanguardia europea tanto en términos de competitividad como de sostenibilidad, haciendo imposible el objetivo de una España Circular en 2030.

\section{BIBLIOGRAFÍA}

BUSTILLO BOLADO, R. O., "Integración y eficiencia de los recursos naturales en el ecosistema urbano", en María Rosario Alonso Ibáñez (Dira), Retos del desarrollo urbano sostenible e integrado, Editorial Tirant lo Blanch, Valencia, 2018, p. 107-132.

ESTEVE PARDO, J., El desconcierto del Leviatán. Política y derecho ante las incertidumbres de la ciencia, Marcial Pons, Madrid, 2009.

ESTEVE PARDO, J., "Decidir y regular en la incertidumbre. Respuestas y estrategias del Derecho Público", en Mercé Darnaculleta I Gardella, José Esteve Pardo y Indra Spiecker gen. Döhmann (Eds.), Estrategias del Derecho ante la incertidumbre y la globalización, Marcial Pons, Madrid, 2015, p. 33-46. 
GONZÁLEZ MEDINA, M., "Del enfoque integrado de desarrollo urbano sostenible de la Unión Europea al paradigma de la gobernanza urbana en España", en María Rosario Alonso lbáñez (Dir $\left.{ }^{a}\right)$, Retos del desarrollo urbano sostenible e integrado, Editorial Tirant lo Blanch, Valencia, 2018, p. 35-64.

DE SADELEER, N., "La economía circular, entre la valorización y la eliminación de residuos", en Revista Aranzadi de Derecho Ambiental, núm. 38, septiembrediciembre 2017, p. 229-246.

DOMÉNECH PASCUAL, G., Derechos fundamentales y riesgos tecnológicos, Centro de Estudios Políticos y Constitucionales, Madrid, 2006.

GARCÍA GARCÍA, S., "Economía circular: 30 años del principio de desarrollo sostenible evolucionan en el nuevo gran objetivo medioambiental de la Unión Europea" en Revista de Estudios Europeos, núm. 71, enero-junio, 2018, <http://www.ree-uva.es/images/numeros/71/2018-71-309-321.pdf> [Última consulta: 12.10.2018]

NOGUEIRA LÓPEZ, A., "Desarrollo urbano sostenible: ¿Actuar localmente sin cambio global?", en Cuadernos de Derecho Local, núm. 46, Fundación Democracia y Gobierno Local, febrero 2018, p. 32-65.

ORTEGA BERNARDO, J., "La gestión de los residuos en el nuevo paquete de la Comisión Europea", en Ambienta: la revista del Ministerio de Medio Ambiente, núm. 117, 2016, p. 64-71,

<http://www.revistaambienta.es/WebAmbienta/marm/Dinamicas/secciones/artic ulos/Juliaor.htm> [Última consulta: 12.10.2018]

SANTAMARÍA ARINAS, R. J, "Aproximación jurídica a las medidas de la Unión Europea para la economía circular", en Ambienta: la revista del Ministerio de Medio Ambiente, núm. 117, 2016, p. 36-45,

$<$ http://www.revistaambienta.es/WebAmbienta/marm/Dinamicas/secciones/artic ulos/Rene.htm > [Última consulta: 12.10.2018]

TARRÉS VIVES, M., "El papel de la normalización internacional en el contexto de la seguridad y el comercio de productos", en Mercé Darnaculleta I Gardella, José Esteve Pardo y Indra Spiecker gen. Döhmann (Eds.), Estrategias del Derecho ante la incertidumbre y la globalización, Marcial Pons, Madrid, 2015, p. 137-154.

\section{FUENTES DOCUMENTALES}

COMISIÓN EUROPEA:

- "Cerrar el círculo: un plan de acción de la UE para la economía circular", Bruselas, 2.12.2015, $<\mathrm{https}: / /$ eurlex.europa.eu/resource.html?uri=cellar:8a8ef5e8-99a0-11e5-b3b701aa75ed71a1.0011.02/DOC_1\&format=PDF> [Última consulta: 12.10.2018]. 
- "Ecodesign Working Plan 2016-2019", Bruselas, 30.11.2016, <https://ec.europa.eu/energy/sites/ener/files/documents/com_2016_773. en_.pdf> [Última consulta: 12.10.2018].

- "Europa 2020: Una estrategia para un crecimiento inteligente, sostenible e integrador", Bruselas, 3.3.2010, <https://eur-lex.europa.eu/legalcontent/ES/TXT/?uri=celex\%3A52010DC2020> [Última consulta: 12.10.2018].

- "Hacia una economía circular: un programa de cero residuos para Europa", Bruselas, 2.7.2014, <https://eur-lex.europa.eu/legalcontent/es/ALL/?uri=CELEX\%3A52014DC0398> [Última consulta: 12.10.2018].

- "2016 Annual Report on Monitoring the Application of European Union Law", $<$ https://ec.europa.eu/info/sites/info/files/file_import/national_factsheet_s pain_2016_en_0.pdf> [Última consulta: 15.6.2018].

- "Una estrategia para el plástico en una economía circular", Estrasburgo, 16.1.2018, <https://eur-lex.europa.eu/legalcontent/ES/TXT/?uri=COM\%3A2018\%3A28\%3AFIN> [Última consulta: 12.10.2018].

EUROSTAT, "Recycling rate of municipal waste", $<$ https://ec.europa.eu/eurostat/tgm/table.do?tab=table\&init=1\&language=en\&pc ode=t2020_rt120\&plugin $=1>$ [Última consulta: 15.9 .2018 ]

GENERALITAT DE CATALUNYA, "Acord GOV/73/2015, de 26 de maig, pel qual s'aprova l'Estratègia d'impuls a l'economia verda i a l'economia circular", $<$ http://mediambient.gencat.cat/web/.content/home/ambits_dactuacio/empresa_ i_produccio_sostenible/economia_verda/impuls/IMPULS-EV_150519.pdf> [Última consulta: 12.10.2018].

JUNTA DE EXTREMADURA, "Marco regional de impulso a la economía verde y economía circular en Extremadura", <http://extremadura2030.com/wpcontent/uploads/2017/03/marco_070617_v.f_sin-anexos.pdf> [Última consulta: 12.10.2018]

MAPAMA, "Estrategia para la producción ecológica 2018-2020",

MAPAMA y MINEICO, "España Circular 2030. Estrategia Española de Economía Circular" (borrador), 2018. <https://www.miteco.gob.es/es/calidad-y-evaluacionambiental/participacion-publica/Residuos-2018-Nota-sobre-proceso-

informacion-publica-estrategia-espanola-economia-circular.aspx> consulta: 27.09.2018].

[Última

MINEICO, Plan Estatal de Investigación Científica y Técnica y de Innovación (2017-2020),

<http://www.ciencia.gob.es/stfls/MICINN/Prensa/FICHEROS/2018/PlanEstatall

DI.pdf> [Última consulta: 9.10.2018] 
MINISTĖRE DE LA TRANSITION ÉCOLOGIQUE ET SOLIDAIRE, "La feuille de route pour l'économie circulaire", <https://www.ecologiquesolidaire.gouv.fr/sites/default/files/FREC\%20anglais.pdf> [Última consulta: 10.10.2018]. 